\title{
Number and Density of AMPA Receptors in Individual Synapses in the Rat Cerebellum as Revealed by SDS-Digested Freeze-Fracture Replica Labeling
}

\author{
Miwako Masugi-Tokita, ${ }^{1,2}$ Etsuko Tarusawa, ${ }^{1,2,3}$ Masahiko Watanabe, ${ }^{4}$ Elek Molnár, ${ }^{5}$ Kazushi Fujimoto, ${ }^{6 \dagger}$ and \\ Ryuichi Shigemoto ${ }^{1,2,3}$ \\ ${ }^{1}$ Division of Cerebral Structure, National Institute for Physiological Sciences, Myodaiji, Okazaki 444-8787, Japan, ${ }^{2}$ Solution Oriented Research for Science \\ and Technology, Japan Science and Technology Agency, Kawaguchi, Saitama 332-0012, Japan, ${ }^{3}$ Department of Physiological Sciences, Graduate University \\ for Advanced Studies, Sokendai 444-8787, Japan, ${ }^{4}$ Department of Anatomy, Hokkaido University, Sapporo 060-8638, Japan, ${ }^{5}$ Medical Research Council, \\ Centre for Synaptic Plasticity, Department of Anatomy, School of Medical Sciences, University of Bristol, Bristol BS8 1TD, United Kingdom, and ${ }^{6}$ Section of \\ Physiological Anatomy, Fukui Prefectural University, Fukui 910-1195, Japan
}

The number of AMPA receptor (AMPAR) is the major determinant of synaptic strength at glutamatergic synapses, but little is known about the absolute number and density of AMPARs in individual synapses. Using SDS-digested freeze-fracture replica labeling, which has high detection efficiency comparable with electrophysiological noise analysis for functional AMPAR, we analyzed three kinds of excitatory synapses in the molecular layer of the adult rat cerebellum. In parallel fiber (PF)-Purkinje cell (PC) synapses, we found large variability in the number (38.1 \pm 34.4 particles per synapse, mean \pm SD; range, $2-178$ particles per synapse) and density (437 \pm 277 particles $/ \mu \mathrm{m}^{2}$; range, $48-1210$ particles $/ \mu \mathrm{m}^{2}$ ) of immunogold-labeled AMPARs. Two-dimensional view and high sensitivity of this method revealed irregular-shaped small AMPAR clusters within synapses. Climbing fiber (CF)-PC synapses had higher number of AMPAR labeling (68.6 \pm 34.5 particles per synapse) than PF-PC and PF-interneuron synapses (36.8 \pm 14.4 particles per synapse). Furthermore, AMPAR density at CF-PC and PF-interneuron synapses was approximately five times higher and more uniform than that at PF-PC synapses. These results suggest input- and target-dependent regulation of AMPAR-mediated synaptic strength.

Key words: glutamate receptor; AMPA receptor; cerebellum; Purkinje cell; synapse; SDS freeze-fracture replica labeling; $\delta 2$ receptor; electron microscopy

\section{Introduction}

The number of AMPA receptor (AMPAR) in postsynaptic sites is widely regarded as a major determinant of synaptic strength, and dynamic changes in AMPAR number underlie the expression of long-term plasticity (Wang and Linden, 2000; Xia et al., 2000; Bredt and Nicoll, 2003; Triller and Choquet, 2005). It is also suggested that difference in the number of AMPAR contributes to the spatial scaling of excitatory inputs (Smith et al., 2003). However, the precise estimation of number and density of AMPAR in synapses has been made only in limited examples such as mossy fiber inputs to cerebellar granule cells (Silver et al., 1996)

Received July 5, 2006; revised Jan. 17, 2007; accepted Jan. 18, 2007.

This work was supported by Solution Oriented Research for Science and Technology from the Japan Science and Technology Agency and Ministry of Education, Culture, Sports, Science, and Technology (R.S.) and Japan Society for the Promotion of Science (M.M.-T.) We thank Hirokazu Hirai for advice in raising the antibody for GluR $\delta 2$, Yugo Fukazawa for helpful discussions, Sachiko Yamada for technical assistance, and Mitsuhiro Kawata and John F. Morris for careful reading of this manuscript.

${ }^{\dagger}$ Deceased, Nov. 28, 2003.

Correspondence should be addressed to Dr. Ryuichi Shigemoto, National Institute for Physiological Sciences, Myodaiji, 0kazaki 444-8787, Japan. E-mail: shigemot@nips.ac.jp.

M. Masugi-Tokita's present address: Department of Anatomy and Neurobiology, Kyoto Prefectural University of Medicine, 465 Kajii-cho Kawaramachi-Hirokoji Kamigyo-ku, Kyoto 602-8566, Japan.

D01:10.1523/JNEUROSCI.2861-06.2007

Copyright $\odot 2007$ Society for Neuroscience $\quad 0270-6474 / 07 / 272135-10 \$ 15.00 / 0$ and climbing fiber (CF) inputs to immature Purkinje cells (PCs) (Momiyama et al., 2003), in which electrophysiological estimation of the functional channel number is possible by noise analysis. Postembedding immunogold labeling for AMPAR has allowed the relative estimation of synaptic AMPAR number (Zhao et al., 1998; Takumi et al., 1999) and its calibration to the number of functional channels deduced from quantal and nonstationary fluctuation analysis (Jonas et al., 1993; Nusser et al., 1998). However, the relationship between the number of functional AMPAR and the immunogold particle number at individual synapses had not been revealed in the same preparation.

Recently, we developed quantitative SDS-digested freezefracture replica labeling (SDS-FRL) to investigate AMPAR number in individual synapses with high sensitivity. Density of immunogold particles was similar to that of functional AMPAR channels estimated by single-synapse stimulation via twophoton uncaging of glutamate and nonstationary fluctuation analysis combined with reconstruction of ultrathin sections for the size measurement of recorded synapses in immature cerebellum (Tanaka et al., 2005). Here we extend our quantitative SDSFRL analysis to parallel fiber (PF)-PC, CF-PC, and PF-interneuron synapses in the molecular layer of adult rat cerebellum, in which such fine electrophysiological analysis is not feasible. 
The cerebellar PC receives two distinct excitatory afferents: PF from granule cells, which generates simple spikes, and CF from inferior olivary neurons, which generates complex spikes (Thach, 1968; Ito, 1984). Interneurons (stellate, basket, and Golgi cells) receive excitatory inputs mostly from $\mathrm{PF}$ in the molecular layer (Palay and Chan-Palay, 1974; Carter and Regehr, 2002). It has been reported that only a few excitatory quanta are needed to reliably trigger stellate cell firing (Carter and Regehr, 2002), whereas in $\mathrm{PC}$, many $\mathrm{PF}$ inputs are required to trigger action potentials (Barbour, 1993). Activation of single CFs reliably fires PCs through numerous numbers of synapses with high release probability (Dittman and Regehr, 1998; Hashimoto and Kano, 1998; Silver et al., 1998). To better understand such distinct efficacy of excitatory transmission, it is essential to examine the number of AMPAR in each type of synapses as well as the membrane properties of postsynaptic cells. Furthermore, variability of AMPAR number and density among the same kind of synapses should reflect input-specific plasticity, which is believed to be a cellular basis for cerebellar motor learning (Wang and Linden, 2000; Ito, 2001). Synaptic weight distribution could also be important to understand learning processes through optimizing information storage in PCs (Brunel et al., 2004). In the present study, highly sensitive SDS-FRL allowed us to estimate precisely the number, density, and location of AMPAR in individual synapses in the adult cerebellum and revealed input- and target-celldependent differences in AMPAR distribution.

\section{Materials and Methods}

SDS-FRL. SDS-FRL was performed with some modifications to the original method described by Fujimoto (1995). Male Sprague Dawley rats (9-14 weeks old) and postnatal day 3 (P3) rats were used in this study. In accordance with the animal experiment committee of the National Institute for Physiological Sciences (Okazaki, Japan), all efforts were made to minimize animal suffering and reduce the number of animals used. For SDS-FRL, rats ( $n=4$ for adult; $n=2$ for P3) were anesthetized with sodium pentobarbital and subjected to transcardiac perfusion with formaldehyde ( $0.5 \%$; freshly depolymerized from paraformaldehyde) in $0.1 \mathrm{~m}$ sodium phosphate buffer. After perfusion, brains were removed, and the cerebella (lobule VIII or IX) were cut into sections $120 \mu \mathrm{m}$ thick by a Microslicer (Dosaka, Kyoto, Japan) and cryoprotected with $32 \%$ glycerol in PBS for $12-16 \mathrm{~h}$. The sections were then frozen by a highpressure freezing machine (HPM 010; Bal-Tec, Balzers, Liechtenstein) and fractured by double replica method in a freeze etching system (BAF 060; Bal-Tec). The fractured faces were replicated by carbon $(5 \mathrm{~nm})$ with an electron beam gun from overhead and shadowed by platinum/carbon positioned at a $25^{\circ}$ angle with rotating $(2.5 \mathrm{~nm})$ or at a $45^{\circ}$ angle $(2 \mathrm{~nm})$ unidirectionally, followed by carbon $(20 \mathrm{~nm})$ applied from overhead. We applied $5 \mathrm{~nm}$ of carbon before platinum to increase the detection efficiency. This procedure, however, increases sizes of intramembrane particles (IMPs), which caused them not to resemble IMPs in conventional freeze-fracture replicas (Landis and Reese, 1974; Harris and Landis, 1986: Rash et al., 2005). The pieces of replica were transferred to $2.5 \%$ SDS containing $0.0625 \mathrm{M}$ Tris and $10 \%$ glycerol, $\mathrm{pH} 6.8$. SDS treatment was performed for $15 \mathrm{~min}$ at $105^{\circ} \mathrm{C}$ with autoclaving, $16 \mathrm{~h}$ at $80^{\circ} \mathrm{C}$ with shaking, or $16 \mathrm{~h}$ at $30^{\circ} \mathrm{C}$ with vigorous stirring. After the treatment with SDS, replicas were washed with three changes of $0.1 \%$ BSA in Trisbuffered saline (TBS) and blocked for $1 \mathrm{~h}$, with two changes of $5 \%$ BSA in TBS. The replicas were then reacted with primary antibodies at room temperature for $1 \mathrm{~h}$, followed by $4^{\circ} \mathrm{C}$ for $36-48 \mathrm{~h}$. For single-labeling experiments, polyclonal rabbit antibody for pan-AMPA $(3 \mu \mathrm{g} / \mathrm{ml})$ (Nusser et al., 1998), monoclonal mouse antibody for glutamate receptor subunit 2 (GluR2) $(6.75 \mu \mathrm{g} / \mathrm{ml}$; Chemicon, Temecula, CA), or polyclonal guinea pig antibody for GluR $\delta 2(0.55 \mu \mathrm{g} / \mathrm{ml})$ was used. The replicas were then washed three times with $0.1 \%$ BSA in TBS, blocked two times with 5\% BSA in TBS for $30 \mathrm{~min}$, and incubated for $1 \mathrm{~h}$ at room temperature, followed by $12-16 \mathrm{~h}$ at $4^{\circ} \mathrm{C}$ or for $2-3 \mathrm{~h}$ at $35^{\circ} \mathrm{C}$ with the secondary antibodies (1:20 dilution) for goat anti-rabbit IgG coupled to $15 \mathrm{~nm}$ gold particles (GE Healthcare, Piscataway, NJ) or goat anti-rabbit IgG coupled to $10 \mathrm{~nm}$ gold particles (British Biocell International, Cardiff, UK) for pan-AMPA, and goat anti-guinea pig IgG coupled to 10 $\mathrm{nm}$ gold particle (British Biocell International) for GluR $\delta 2$ in 5\% BSA/ TBS. For double-labeling experiments for pan-AMPA $(3 \mu \mathrm{g} / \mathrm{ml})$ and monoclonal mouse antibody for GluR2 $(6.75 \mu \mathrm{g} / \mathrm{ml}$; Chemicon), panAMPA ( 3 or $0.3 \mu \mathrm{g} / \mathrm{ml}$ ) and polyclonal guinea pig antibody for vesicular glutamate transporter 2 (VGluT2) $(8.9 \mu \mathrm{g} / \mathrm{ml})$ (Miyazaki et al., 2003), or polyclonal rabbit antibody for Kv4.3 (2 $\mu \mathrm{g} / \mathrm{ml}$; Alomone Labs, Jerusalem, Israel) and polyclonal guinea pig antibody for metabotropic GluR1 $\alpha$ $(\mathrm{mGluR} 1 \alpha)(50 \mu \mathrm{g} / \mathrm{ml})$, a mixture of primary antibodies was applied, followed by three washes in $0.1 \%$ BSA in TBS, blocking in 5\% BSA/TBS, and an incubation in a mixture of secondary antibodies [goat anti-rabbit IgG coupled to $10 \mathrm{~nm}$ gold particle (British Biocell International) and goat anti-mouse IgG coupled to $15 \mathrm{~nm}$ gold particle (GE Healthcare)] for pan-AMPA and GluR2 [goat anti-rabbit IgG coupled to $5 \mathrm{~nm}$ gold particle (British Biocell International) and goat anti-guinea pig IgG coupled to $15 \mathrm{~nm}$ gold particle (British Biocell International)] for pan-AMPA and VGluT2 or [goat anti-rabbit IgG coupled to $15 \mathrm{~nm}$ gold particle (GE Healthcare) and goat anti-guinea pig IgG coupled to $10 \mathrm{~nm}$ gold particle (British Biocell International)] for Kv4.3 and $\mathrm{mGluR} 1 \alpha$ for $1 \mathrm{~h}$ at room temperature, followed by $12-16 \mathrm{~h}$ at $4^{\circ} \mathrm{C}$ or for $2-3 \mathrm{~h}$ at $35^{\circ} \mathrm{C}$. We did not analyze labeling for mGluR $1 \alpha$ shown in Figure $3 F$ in the present study. For double-labeling experiments for pan-AMPA $(0.3$ or $3 \mu \mathrm{g} / \mathrm{ml})$ and GluR $\delta 2(0.22 \mu \mathrm{g} / \mathrm{ml})$ or triple-labeling experiments for pan-AMPA $(0.3$ or $3 \mu \mathrm{g} / \mathrm{ml})$, VGluT2 $(8.9 \mu \mathrm{g} / \mathrm{ml})$, and GluR $\delta 2(0.22 \mu \mathrm{g} / \mathrm{ml})$, to avoid reciprocal interaction, replicas were first reacted with pan-AMPA or panAMPA and VGluT2 and then secondary respective antibodies, followed by incubation in the GluR $\delta 2$ antibody and its secondary antibody. When one of the primary antibodies was omitted, no immunoreactivity for the omitted primary antibody was observed. Preadsorption of the panAMPA antibody with the glutathione S-transferase/GluR1-GluR4 fusion protein used for immunization (Nusser et al., 1998) completely abolished the immunoreactivity. After immunogold labeling, the replicas were immediately rinsed three times with $0.1 \%$ BSA/TBS, washed twice with distilled water, and picked up onto grids coated with pioloform (Agar Scientific, Stansted, Essex, UK).

Condition of fixation. To optimize condition of fixation, we first perfused animals with formaldehyde $(0.5,1,2$, and $4 \%$; freshly depolymerized from paraformaldehyde) in $0.1 \mathrm{M}$ sodium phosphate buffer or saline only. In unfixed tissue and those fixed with low concentration of paraformaldehyde $(0.5 \%)$, we often found complete "flattening" of PF-PC synapses (supplemental Fig. 2, available at www.jneurosci.org as supplemental material), which are usually located in spheroidal spine heads in intact PCs. However, we found this rather advantageous because probability to collect complete surface of synapses was increased with the flattening, and we detected no significant difference in AMPAR labeling density between the complete (and flattened) synapses and incomplete synapses found often on spine-like structures. In tissues fixed with higher concentration of paraformaldehyde (2-4\%) or glutaraldehyde $(1.5 \%)$, fracturing often occurred at the neck of the spine, and only incomplete areas of the synaptic sites could be observed (supplemental Fig. 2, available at www.jneurosci.org as supplemental material). Although the result from unfixed tissue was comparable with that from $0.5 \%$ paraformaldehyde-fixed tissue, we chose fixed one because of its stability for quantitative analysis.

Quantification of immunoreactivity in SDS-FRL. Replicas were observed in a Tecnai 12 electron microscope (FEI Company, Hillsboro, OR) and photographed to obtain prints at a magnification of $125,000-$ $213,000 \times$. Immunogold particles were counted in excitatory postsynaptic areas indicated by clusters of IMP (Landis and Reese, 1974; Harris and Landis, 1986). Particles within $30 \mathrm{~nm}$ from the edge of synaptic sites were included in the analysis because they can be distant from the epitope (Matsubara et al., 1996). The area of synapses was calibrated by using a calibration grid (Ted Pella, Redding, CA). The outline of synaptic sites was demarcated freehand (Fig. $1 B, D$, red), and their area was measured by Scion Image (Scion, Frederick, MD). Background labeling for pan- 
AMPA receptors was estimated by counting immunogold particles on the protoplasmic face (P-face) of Purkinje cell bodies and dendrites.

Criteria for analysis. For all of the analysis, synapses indicated by IMP clusters $\left(>0.007 \mu \mathrm{m}^{2}\right)$ and molecular markers were randomly chosen. To obtain the maximum size of synapses, we took en face images of synapses by tilting the sample. For PF-PC synapses, we analyzed the synaptic sites which had more than three immunogold particles for GluRס2. For CF-PC synapses, IMP clusters on the exoplasmic face (Eface) having VGluT2 labeled opposing P-face within $1 \mu \mathrm{m}$ were analyzed. For PF-interneuron synapses, we analyzed GluR $\delta 2$-negative synapses on the E-face that have Kv4.3-labeled opposing P-face with >18.1 particles/ $\mu \mathrm{m}^{2}$, which is $3 \mathrm{SD}$ times higher than the mean value for PCs $(9.1 \pm 3.0$ particles $/ \mu \mathrm{m}^{2}$; data not shown; range, $2.4-16.3 ; n=25$ ). For analysis of Kv4.3 labeling density on dendrites, each P-face larger than $0.3 \mu \mathrm{m}^{2}$ was included in the analysis. For PF-interneuron synapses in supplemental Figure 3 (available at www.jneurosci.org as supplemental material), we defined interneuron dendrites as having no branches, $<1.5 \mu \mathrm{m}$ in diameter, and having more than two small synapses $\left(<0.05 \mu \mathrm{m}^{2}\right)$.

Statistics. Statistical analysis was done by SPSS (SPSS, Chicago, IL). Data were represented by mean $\pm \mathrm{SD}$ ( $n=$ number of synapses) unless stated otherwise. Distribution and mean values between groups were compared by the $t$ test after confirming the Gaussian distribution by Shapiro-Wilk test. For the data with non-Gaussian distribution, values were compared by Kolmogorov-Smirnov test and Mann-Whitney $U$ test. For analysis of P3 rats, measurements in two animals were pooled because the density for immunogold particles on IMP clusters was not significantly different between the two animals.

Freeze substitution and Lowicryl embedding. Male SD rats (9-14 weeks old) were anesthetized with sodium pentobarbital and subjected to transcardiac perfusion with formaldehyde (2\%; freshly depolymerized from paraformaldehyde) in $0.1 \mathrm{~m}$ sodium phosphate buffer. Lobules VIII or IX of the cerebellum were sliced at $500 \mu \mathrm{m}$, cryoprotected in graded concentrations of phosphate-buffered glycerol, and rapidly frozen in liquid propane in a cryofixation module (EM CPC; Leica, Wetzlar, Germany). The slices were then transferred to $2 \%$ uranyl acetate dissolved in anhydrous methanol $\left(-90^{\circ} \mathrm{C}\right)$ in a freeze substitution system (EM AFS; Leica). The temperature was raised stepwise to $-45^{\circ} \mathrm{C}$. The samples were infiltrated with Lowicryl HM20 resin (Electron Microscopy Sciences, Fort Washington, PA) and polymerized by UV light.

Postembedding immunocytochemistry. A similar method was used as described previously (Kulik et al., 2002). Consecutive ultrathin sections were mounted on nickel grids, incubated in $50 \mathrm{~mm}$ TBS containing $0.1 \%$ Triton X-100 (TBST), 2\% human serum albumin (HSA) (Sigma, St. Louis, MO) for $1 \mathrm{~h}$, and then with primary antibody (in TBST containing $2 \% \mathrm{HSA}$ ) for $12-16 \mathrm{~h}$ at room temperature. A mixture of primary antibodies for pan-AMPA $(9.4 \mu \mathrm{g} / \mathrm{ml})$, VGluT1 $(14.8 \mu \mathrm{g} / \mathrm{ml})$ (Miyazaki et al., 2003), and VGluT2 $(0.48 \mu \mathrm{g} / \mathrm{ml})$ were used. After washing in TBS for $30 \mathrm{~min}$, sections were incubated with a mixture of secondary antibodies [goat anti-rabbit IgG coupled to $5 \mathrm{~nm}$ gold particle (British Biocell International), goat anti-rat IgG coupled to $10 \mathrm{~nm}$ gold particle (British Biocell International), and goat anti-guinea pig IgG coupled to $15 \mathrm{~nm}$ gold particle (British Biocell International)] in TBST containing 2\% HSA and $5 \mathrm{mg} / \mathrm{ml}$ polyethylene glycol for $3-5 \mathrm{~h}$ at room temperature. When one of the primary antibodies was omitted, no immunoreactivity for the omitted primary antibody was observed. After several washes in TBS and distilled water, sections were counterstained with saturated aqueous uranyl acetate, followed by lead citrate.

Quantification of immunoreactivity for postembedding labeling. Reacted sections were photographed in 10-15 serial sections and printed at a magnification of $52,000 \times$. Synapses made by axon terminals on PC spines and interneuron dendrites were included in the analysis only if they were fully present within the serially sectioned volume of tissue. Interneuron dendrites were identified by several asymmetrical synapses on the shaft and lack of spines. The length of the synaptic junction was measured on each ultrathin section, and the synaptic area was calculated by multiplying the synaptic length in each section with the estimated thickness of the ultrathin sections (e.g., $90 \mathrm{~nm}$ ); areas were then summed from all sections through each synapse. Labeling density was obtained by dividing total gold number by total synaptic area of each synapse.
Antibodies. The specificity of pan-AMPA (Nusser et al., 1998), GluR2 (Vissavajjhala et al., 1996), VGluT1 and VGluT2 (Miyazaki et al., 2003), and Kv4.3 (Hsu et al., 2003) (Alomone Labs) antibodies has been extensively characterized previously. An antibody for GluR $\delta 2$ was newly raised in guinea pig using the same peptide (amino acid residues 505-514) used in a previous study (Hirai et al., 2003) and gave an identical labeling pattern as that obtained with a rabbit GluR $\delta 2$ antibody (Hirai et al., 2003).

\section{Results}

\section{AMPAR labeling in the molecular layer of the cerebellum}

SDS-FRL can visualize the two-dimensional distribution of membrane proteins with high resolution and high sensitivity (Fujimoto, 1995; Pereda et al., 2003; Tanaka et al., 2005). Using SDS-FRL, we analyzed the AMPAR distribution in the molecular layer of adult rat cerebellum with an antibody against highly conserved extracellular amino acid residues of GluR1-GluR4 (panAMPA) (Nusser et al., 1998). The pan-AMPA antibody selectively reacts with AMPA but not kainate receptor subunits (Nusser et al., 1998). Layers of the cerebellar cortex were easily identified with light microscopy (Fig. 1A), and postsynaptic membrane areas of excitatory synapses were clearly indicated with aggregation of IMPs on the E-face at the electron microscopic level (Fig. $1 B-F$ ) as described previously (Landis and Reese, 1974; Harris and Landis, 1986). In the molecular layer, immunogold particles for AMPARs were mostly found on such aggregation of IMPs. On the E-face, almost all IMP clusters were labeled for AMPAR with various levels of gold particle density (Fig. $1 B-D$ ). In the majority of synapses, immunogold particles formed small clusters within individual synapses (Fig. $1 B, C, F$ ), whereas very dense and homogeneous labeling was occasionally found all over the IMP clusters (Fig. 1D). To confirm specificity of the pan-AMPA labeling, we performed single and double labeling with another antibody selective for GluR2 subunit, which is included in most AMPAR channels expressed in PCs (Zhao et al., 1998). Overall labeling pattern for GluR2 was very similar to that for pan-AMPA (Fig. 1E), and, in double-labeled materials, immunogold particles for pan-AMPA and GluR2 were colocalized in the same clusters in synaptic sites (Fig. $1 F$ ). Similar pattern of GluR2 labeling was observed in wild-type but not GluR2-deficient mice (kindly provided by Dr. Sprengel, MaxPlanck-Institute for Medical Research, Heidelberg, Germany) (data not shown). Stereoscopic viewing (Fig. 1C) revealed that gold particles for pan-AMPA were located beneath the replica excluding nonspecific labeling on the side coated with carbon and platinum (Rash and Yasumura, 1999). Furthermore, labeling for pan-AMPA was mostly abolished $\left(45.2 \pm 39.0\right.$ particles $/ \mu \mathrm{m}^{2}$; $n=33$ ) at PF-PC synapses of GluR2 and GluR3 double knockout mice (supplemental Fig. 1, available at www.jneurosci.org as supplemental material; provided by Dr. Sprengel), which is consistent with the finding that most of AMPARs at PF-PC synapses consist of GluR2 and GluR3 (Keinänen et al., 1990; Martin et al., 1993; Sato et al., 1993). All of these results verify the specificity of replica labeling for pan-AMPA in the cerebellum.

\section{Calibration of AMPAR labeling using P3 cerebellum}

To estimate sensitivity of the SDS-FRL for AMPARs, we measured immunogold labeling density of P3 PCs (Fig. 2), which solely receive CF afferents (Altman and Bayer, 1997). Recently, we found that the density for AMPAR particles obtained by SDSFRL had a value close to that of functional AMPAR channels in acute cerebellar slices prepared from P3 rats (Tanaka et al., 2005). In perfusion-fixed $\mathrm{P} 3$ cerebellum, we analyzed the AMPAR density under the same condition that was used for adult rats in the 

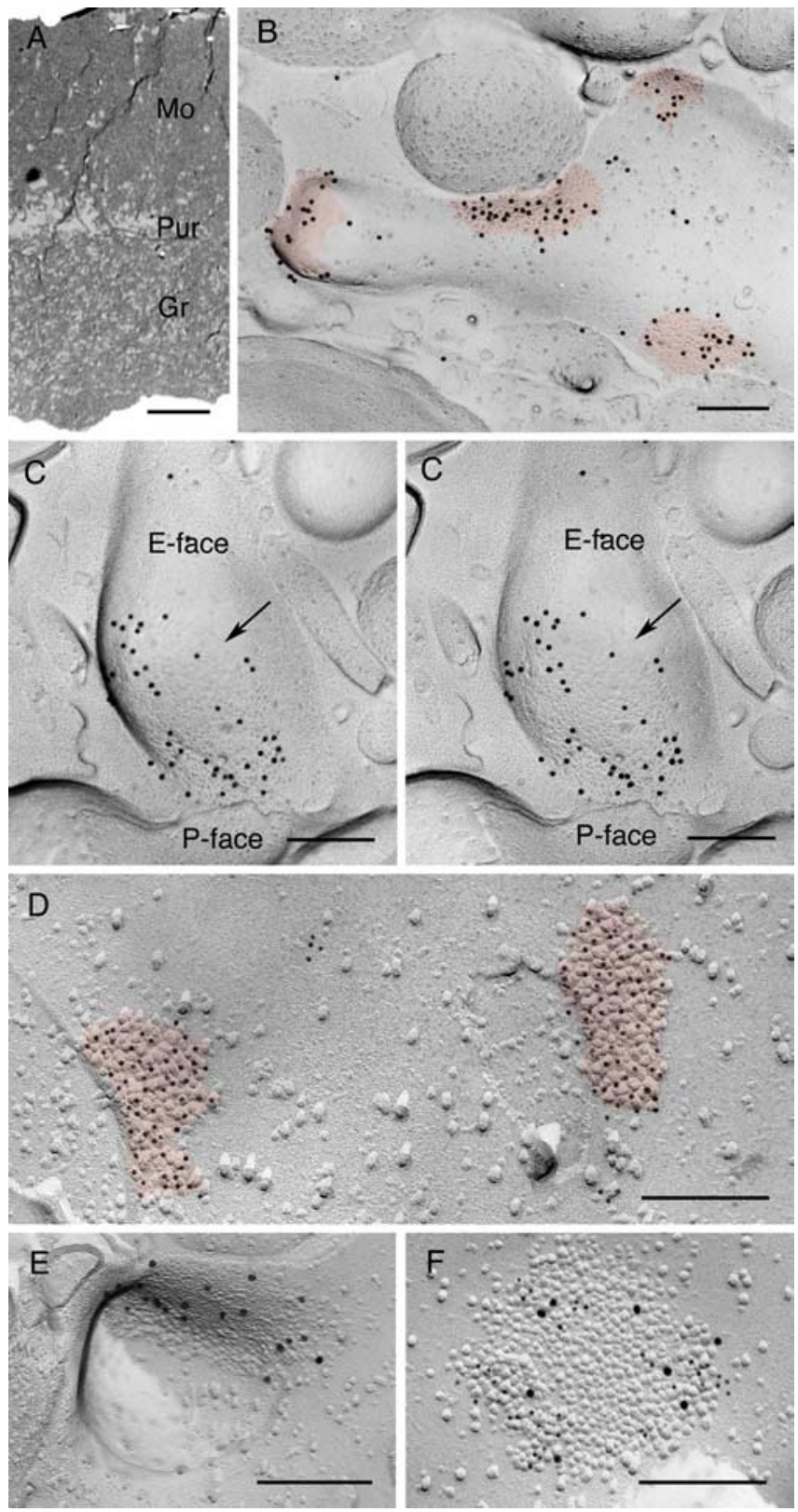

Figure 1. Distribution of AMPARs in the molecular layer of the cerebellum as revealed by SDS-FRL. $A$, The molecular (Mo), Purkinje cell (Pur), and granular (Gr) layers are visible under the light microscopic view of replica. $\boldsymbol{B}, \boldsymbol{C}$, Clusters of IMPs (colored in $\boldsymbol{B}$, arrow in $\boldsymbol{C}$ ) on the E-face indicate postsynaptic sites. Immunolabeling for pan-AMPA (GluR1-GluR4, 15 nm immunogold particles) is mostly found in the IMP clusters. Stereoscopic view reveals that all particles are beneath the replica (C). Immunolabeling for AMPARs is inhomogeneous within individual synapses and also highly variable in different synapses. D, Occasionally, homogeneous labeling for AMPARs ( $10 \mathrm{~nm}$ particles) can be found in IMP clusters (colored). $\boldsymbol{E}$, Immunolabeling for GluR2 $(15 \mathrm{~nm})$ is observed in IMP clusters. $\boldsymbol{F}$, Small clusters of immunogold particles for pan-AMPA (10 $\mathrm{nm}$ ) and GluR2 (15 nm) are colocalized in synaptic sites. Rotary and unidirectional shadowings were used for $\boldsymbol{B}, \boldsymbol{C}$ and $\boldsymbol{D}-\boldsymbol{F}$, respectively. Scale bars: $\boldsymbol{A}, 100 \mu \mathrm{m} ; \boldsymbol{B}-\boldsymbol{F}, 250 \mathrm{~nm}$.

present study. In these analyses, we used secondary antibodies coupled to $5 \mathrm{~nm}$ gold particles because of its higher detection efficiency than those with larger immunogold particles. AMPAR labeling in CF-PC synapses in P3 PCs was intense and homogeneous (Fig. 2); density of immunogold particles was $1740 \pm 399$ particles $/ \mu \mathrm{m}^{2}$ [mean $\pm \mathrm{SD}$; coefficient of variation $(\mathrm{CV})$ of 0.23 ; $n=52$ ], which is comparable with the estimated value of functional AMPAR channel density (Tanaka et al., 2005). Although
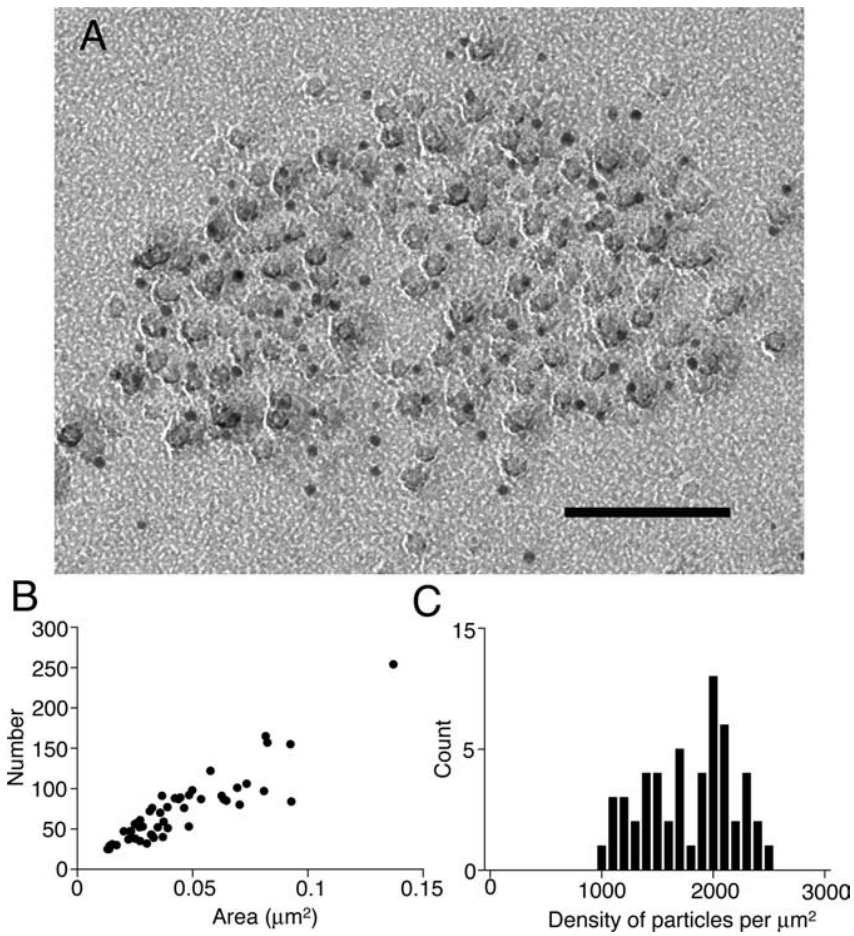

Figure 2. AMPAR labeling at $\mathrm{CF}-\mathrm{PC}$ synapses of $\mathrm{P} 3$ rat. $A$, Dense and homogeneous immunolabeling for AMPAR ( $5 \mathrm{~nm}$ particles) is observed in synapses indicated by the IMP cluster. Rotary shadowing was used. Scale bar, $100 \mathrm{~nm}$. B, Number of particles in each synapse is plotted against an area of IMP clusters showing a linear correlation. $C$, Distribution of immunogold particle density for AMPARs.

the labeling efficiency could be variable in different preparations, these results suggest that the AMPAR labeling under the present condition of SDS-FRL has virtually one-to-one detection efficiency to functional AMPAR channels.

In the present study, AMPAR labeling density in P3 rat $\left(1740 \pm 399\right.$ particles $\left./ \mu \mathrm{m}^{2}\right)$ was 1.9 times higher than that of the previous study $\left(910 \pm 36\right.$ particles $\left./ \mu \mathrm{m}^{2}\right)$ measured in unfixed acute slice preparation (Tanaka et al., 2005). One reason to explain the higher sensitivity in perfusion-fixed brain in the present study is increased number of gold particles that bind to one channel molecule, and the other is increased number of channel molecules accessed by the antibody. To examine these possibilities, we analyzed the density of extrasynaptic labeling using different concentrations of the antibody. Extrasynaptic labeling was very sparse, and we considered gold particles located within $50 \mathrm{~nm}$ to each other as one gold cluster that could derive from the same channel molecule (Matsubara et al., 1996). When antibody concentration was increased from 0.3 to $3.0 \mu \mathrm{g} / \mathrm{ml}$, density of particles and clusters in extrasynaptic membrane increased by $50 \%$, whereas particle number per cluster did not change at all (data not shown). This result indicates that labeling of one channel with multiple particles is rare in our sample because, if more than two primary antibodies can bind to one channel, higher concentration of antibodies would increase the number of particles bound to one epitope. The higher sensitivity in this study thus seems to be ascribable to increased number of accessible channel molecules, and sensitivity close to unity (Tanaka et al., 2005) may still remain in the present preparation.

Large variability in AMPAR labeling among PF-PC synapses In the adult cerebellar molecular layer, three different types of excitatory synapses are distributed: PF-PC, CF-PC, and PF-in- 

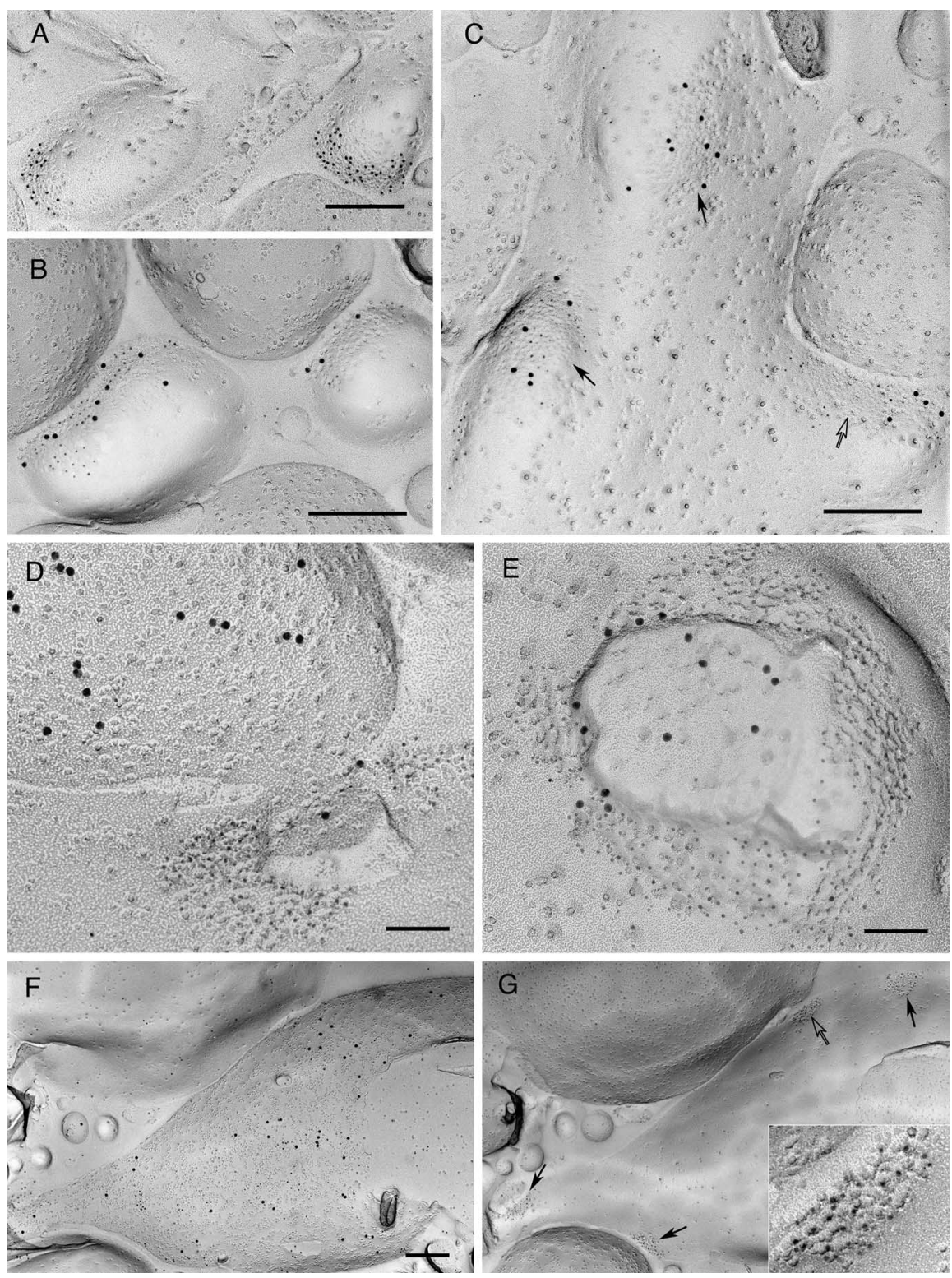

Figure 3. AMPAR distribution in adult PF-PC, CF-PC, and PF-interneuron synapses. $A$, Immunolabeling for GluR $\delta 2(10 \mathrm{~nm}$ particles) is observed in IMP clusters found on the $E$-face of $P($ spines, showing very homogeneous labeling within individual synapses and also in different synapses. $\boldsymbol{B}$, Immunolabeling for AMPAR ( $5 \mathrm{~nm}$ ) with high (left) or low (right) densities of immunogold is observed in PF-PC synapses identified by labeling for GluR $\delta 2(15 \mathrm{~nm})$. C, Some synapses are fractured with partial synaptic areas (open arrow), whereas others are flattened and fractured completely, showing whole areas of synapses (arrows). $\boldsymbol{D}_{\text {, }}$ E, Localization of AMPAR labeling $(5 \mathrm{~nm})$ in the CF-PC synapses identified by labeling for VGluT2 (15 nm) on opposing P-face of presynaptic membrane in the molecular layer. Note that the central area of $\boldsymbol{E}$ was not shadowed with platinum. This makes the 5 nm gold easily discerned on IMPs (above bottom center), but they are more difficult to discern when the IMPs were shadowed with platinum (right side). $\boldsymbol{F}$, Immunolabeling for Kv4.3 $(15 \mathrm{~nm})$ is diffusely observed on the $P$-face of interneurons. Smaller particles are for mGluR1 $\alpha$, which is not related to this report. $\mathbf{G}$, Immunolabeling for AMPARs $(5 \mathrm{~nm})$ is dense and homogeneous in IMP clusters (arrows) in E-face of interneurons identified by matching the complementary P-face shown in $\boldsymbol{F}$, which is labeled for Kv4.3. Inset shows one of the synapses (open arrow). Rotary shadowing was used for this figure. Scale bars, $A-C, F, G, 250 \mathrm{~nm} ; \boldsymbol{D}, \boldsymbol{E}, 100 \mathrm{~nm}$.

terneuron synapses. To identify PF-PC synapses in the replica membranes, we used labeling for GluR $\delta 2$, which is selectively expressed in this type of synapse (Landsend et al., 1997; Zhao et al., 1997). Dense and homogeneous immunogold labeling for GluR $\delta 2$ was often found in IMP clusters on the E-face of spinelike structures in the molecular layer (Fig. $3 A$ ). The same pattern of labeling was observed in wild-type but not GluR $\delta 2$-deficient mice (Kashiwabuchi et al., 1995) (data not shown). For double labeling of AMPAR and GluR $\delta 2$ proteins, the two antibodies were sequentially applied to avoid potential interference of primary antibodies. Virtually all PF-PC synapses identified with the GluR $\delta 2$ labeling were positive for AMPAR, although with highly variable density of immunogold particles (Figs. $3 B, C, 4 A, C)$. Some synapses were fractured through the complete synaptic areas [complete synapses (Fig. 3C, arrows)], whereas the others were fractured through partial synaptic areas [incomplete synapses (Fig. 3 B, $C$, open arrow)]. The complete synapses positive for both AMPAR and GluR $\delta 2$ are probably spine synapses that were flattened in the process of preparing samples with low concentration of fixatives (supplemental Fig. 2, available at www.jneurosci.org as supplemental material). Synapses on spine-like structures were mostly fractured incompletely. Therefore, we first analyzed the number and density of AMPAR labeling of complete and incomplete synapses separately (see Figs. 4-6). We found no significant difference in receptor density between complete and incomplete synapses; therefore, we pooled them in subsequent figures. For the measurement of receptor numbers, we included only complete synapses. The number of immunogold particles in the complete synapses was highly variable (Fig. 4A) (36.4 \pm 33.4 particles; CV of 0.92 ; range, $2-178 ; n=52$ ), although linear correlation between the number of gold particles and area of synaptic sites was found (Fig. 4A) $(p<0.01$, Spearman's rank correlation; $r=0.79$; $n=52$ ). The density of particles was also variable, and its distribution was positively skewed (Fig. 4C) $(416 \pm 268$ particles $/ \mu \mathrm{m}^{2}$; CV of 0.64 ; range, 48.4-1170; $n=52$ ). No significant difference was found between medians of immunogold particle density in complete and incomplete synapses (396 and 399 particles/ $\mu \mathrm{m}^{2}$ for complete and incomplete, respectively; $p>0.05$, Mann-Whitney $U$ test). In contrast with the large variability in AMPAR labeling, the labeling for GluR $\delta 2$ in synaptic sites was very constant and homogeneous (Fig. 4D) (934 \pm 170 particles/ $\mu \mathrm{m}^{2}$; CV of 0.18). To determine whether the variability in AMPAR labeling is attributable to the difference in depth within the molecular layer, we analyzed the number and density of particles at PF-PC synapses in the superficial, middle, and deep parts of the molecular layer. No significant difference was detected between numbers, densities, and their distributions obtained from these three layers (Fig. 5) ( $p>0.05$, Mann-Whitney $U$ test; $p>0.05$, Kolmogorov-Smirnov test). The density of extrasynaptic AMPAR labeling was very low $\left(10.3 \pm 16.6\right.$ particles $\left./ \mu \mathrm{m}^{2}\right)$ and had no relation with the distance from synapses (supplemental Fig. 4, available at www.jneurosci.org as supplemental mate- 

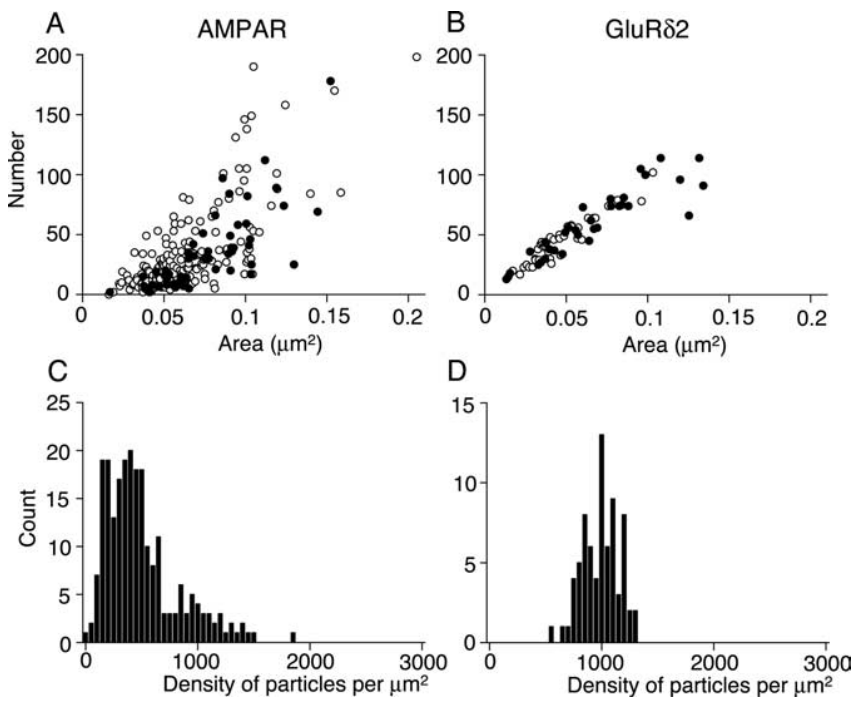

Figure 4. Number and density of immunogold particles for AMPAR and GluR $\delta 2$ at PF-PC synapses. $\boldsymbol{A}, \boldsymbol{B}$, Number of particles for pan-AMPA $(\boldsymbol{A})$ and GluR $\delta 2(\boldsymbol{B})$ in each PF-PC synapse is plotted against area of IMP clusters. $C, D$, Distribution of particle density in synapses for panAMPA ( $\boldsymbol{C}$ ) and GluR $\delta 2(\boldsymbol{D})$, showing positively skewed and Gaussian distribution, respectively. Filled and open circles indicate complete and incomplete synapses, respectively.

rial). Background estimated on the P-face of PCs was extremely low $\left(<5.4\right.$ particles $\left./ \mu \mathrm{m}^{2}\right)$.

\section{Homogeneous labeling for AMPAR at CF-PC and $\mathrm{PF}$-interneuron synapses}

To identify CF-PC and PF-interneuron synapses, we used labeling for VGluT2, which is selectively expressed in CF terminals in the molecular layer (Hioki et al., 2003), and labeling for Kv4.3, an A-type $\mathrm{K}^{+}$channel subunit expressed strongly in basket cells and stellate cells but not in PCs in the adult cerebellum (Hsu et al., 2003). Specificity of immunolabeling for VGluT2 and Kv4.3 were verified with preadsorption of the antibodies with a VGluT2 fusion protein (Miyazaki et al., 2003) and Kv4.3-specific synthetic peptide (residues 451-467), respectively (data not shown). Immunolabeling for VGluT2 was found on the P-face of CF terminals, and very dense and homogeneous AMPAR labeling was found in the postsynaptic sites opposed to the VGluT2-positive P-face (Fig. 3D,E). The number of gold particles $(67.6 \pm 38$ particles; CV of 0.56; range, 25-211) and area of synaptic sites in CF-PC synapses had a strong linear correlation (Fig. 6A) $(p<$ 0.01 , Spearman's rank correlation; $r=0.92 ; n=27$ ), indicating a homogeneous density of AMPARs in this type of synapse. The density of particles was four to five times higher (Fig. 6C) (1920 \pm 303 particles $/ \mu \mathrm{m}^{2}$; CV of 0.16 ; range, $\left.1350-2520 ; n=27\right)$ than that in PF-PC synapses. For identification of interneuron synapses, we matched the P-face labeled strongly for Kv4.3 (Fig. 3F) and complementary E-face labeled with AMPAR particles (Fig. $3 G$ ). For matching the complementary faces produced by double replica method, we used lower magnifications as shown in Figure $1 A$ for orientation. Intense labeling for AMPARs was observed in relatively small IMP clusters, all of which were positive (Fig. $3 G$ and inset). The number of gold particles (33.6 \pm 14.1 particles; CV of 0.42 ; range, $19-61 ; n=11)$ and area of synaptic sites had a strong linear correlation (Fig. $6 B)(p<0.01$, Spearman's rank correlation; $r=0.93$ ), indicating a constant density of AMPAR labeling, which was five to six times higher (Fig. 6D) (2350 \pm 403 particles $/ \mu \mathrm{m}^{2}$; CV of 0.16 ; range, $\left.1730-2980 ; n=11\right)$ than that in PF-PC synapses. It is conceivable that, in CF-PC and PF- interneuron synapses, saturation of immunogold labeling may produce a highly homogeneous particle density. To exclude this possibility, we examined AMPAR labeling with 10 times diluted antibody for pan-AMPA (supplemental Fig. 3, available at www.jneurosci.org as supplemental material). Although the density of immunogold particles was $\sim 70 \%$ of that with the original concentration of the antibody (CF-PC, $1550 \pm 166$ and $2090 \pm$ 149 particles $/ \mu \mathrm{m}^{2}$ for 0.3 and $3 \mu \mathrm{g} / \mathrm{ml}$, respectively; PF-interneuron, $1510 \pm 273$ and $2220 \pm 274$ particles $/ \mu \mathrm{m}^{2}$ for 0.3 and 3 $\mu \mathrm{g} / \mathrm{ml}$, respectively), variability of labeling density remained low for CF-PC (CV of 0.11) and PF-interneuron (CV of 0.18) synapses. These results indicate that $\mathrm{CF}-\mathrm{PC}$ and $\mathrm{PF}-$ interneuron synapses have higher and more homogeneous density of AMPARs than PF-PC synapses.

\section{Comparison of SDS-FRL and conventional postembedding method}

Finally, we compared the distribution of AMPAR particles obtained by SDS-FRL method with that by conventional postembedding method, which has been widely used to determine the synaptic localization of receptors. Triple labeling in serial ultrathin sections was performed using antibodies for pan-AMPA, VGluT1 (for marking PF terminals) (Miyazaki et al., 2003), and VGluT2 (for marking CF terminals). Immunolabeling for AMPAR in PF-PC synapses was highly variable (Fig. 7A, inset). The number and density of immunogold particles were $16 \pm 17.9$ (CV of $1.12 ; n=140)$ and $153 \pm 155$ (CV of $1.02 ; n=140$ ), respectively, and the distribution of density was skewed toward larger values (Fig. 8A,D) $(p<0.001$, Shapiro-Wilk test). At $\mathrm{CF}-\mathrm{PC}$ and $\mathrm{PF}-$ interneuron synapses, dense and homogeneous AMPAR labeling was observed along postsynaptic densities (Fig. $7 B-E)$. The density of immunogold particles was three to four times higher (Fig. 8E,F) (CF-PC, mean density, $575 \pm 142$ particles $/ \mu \mathrm{m}^{2}$; range, $313-922 ; \mathrm{CV}$ of $0.25 ; n=45 ; \mathrm{PF}$-interneuron, mean density, $533 \pm 122$ particles $/ \mu \mathrm{m}^{2}$; range, $324-867$; $\mathrm{CV}$ of $0.23 ; n=49$ ) than that at PF-PC synapses, and there was a strong linear correlation between the number of gold particles and area of synaptic sites (Fig. $8 B, C$ ) (CF-PC, $p<0.01$; $r=0.89$; mean number, $64.9 \pm 36.9$ particles; range, $15-206 ; n=45$; PF-interneuron, $p<0.01 ; r=0.86$; mean number, $28.2 \pm 11.4$ particles; range, $6-51 ; n=49)$. These results confirm our findings and indicate that SDS-FRL has three to four times higher sensitivity compared with the conventional postembedding method.

\section{Discussion}

In the present study, we obtained reliable estimates for the number of synaptic AMPARs in the adult rat cerebellum using highly sensitive freeze-fracture replica labeling. Our results indicate that virtually all excitatory synapses in the molecular layer have AMPARs, and their number and density are distinct and variable depending on the input and target cell types. The large variability in AMPAR number and density at PF-PC synapses may reflect distinct regulation of individual synaptic efficacy through AMPAR turnover in this type of synapse.

\section{Establishment of highly sensitive SDS-FRL}

Localization of AMPARs in CNS synapses has been extensively investigated by postembedding immunogold labeling method (Baude et al., 1995; Landsend et al., 1997; Nusser et al., 1998; Zhao et al., 1998; Takumi et al., 1999). Our SDS-FRL method has several advantages over the conventional postembedding method. First of all, sensitivity to detect AMPARs is much higher in SDS-FRL and comparable with the most sensitive electrophys- 

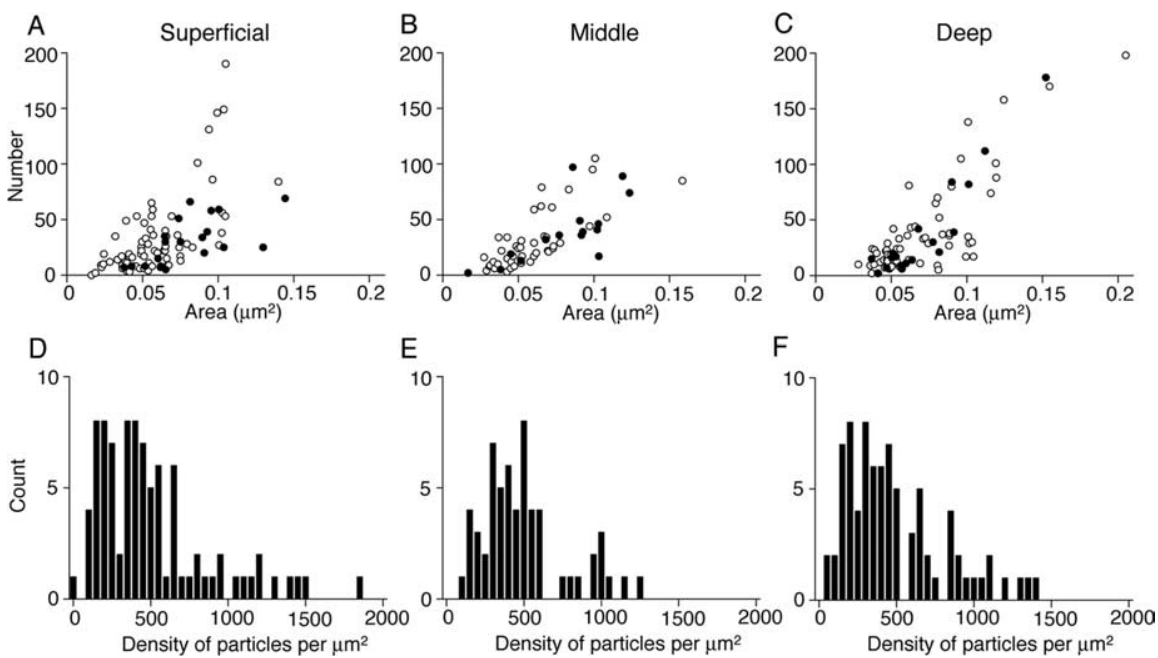

Figure 5. Comparison of AMPAR labeling in PF-PC synapses in different depths of the molecular layer. Number and density of immunogold particles for AMPAR in PF-PC synapses were analyzed in superficial, middle, and deep one-fifth of the molecular layer. No significant difference in density ( $p>0.05$, Mann-Whitney $U$ test) and distribution ( $p>0.05$, Kolmogorov-Smirnov test) of AMPAR-associated gold particles was detected between layers of different depth. Filled and open circles indicate complete and incomplete synapses, respectively.
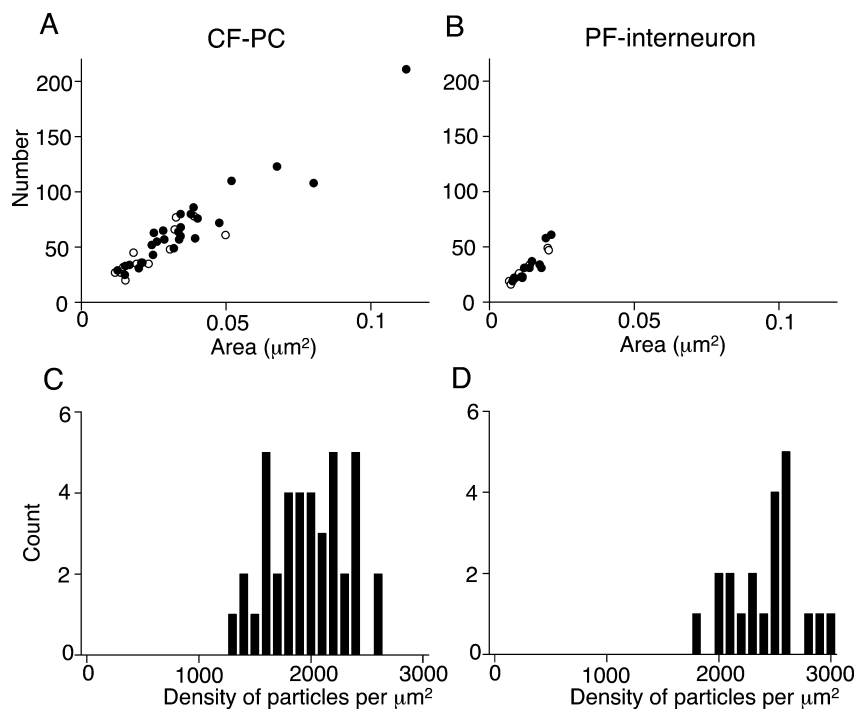

Figure 6. Homogeneous density of AMPAR in CF-PC and PF-interneuron synapses. $\boldsymbol{A}, \boldsymbol{B}$, Number of gold particles in $\mathrm{CF}-\mathrm{PC}(\boldsymbol{A})$ and $\mathrm{PF}$-interneuron $(\boldsymbol{B})$ synapses is plotted against area of synapses. Filled and open circles indicate complete and incomplete synapses, respectively. Linear correlation is evident between gold particle number and synapse size. C, D, Density of gold particles in $\mathrm{CF}-\mathrm{PC}(\boldsymbol{C})$ and $\mathrm{PF}-$-interneuron $(\boldsymbol{D})$ synapses shows Gaussian distribution.

iological analysis (Tanaka et al., 2005). This is probably because (1) AMPAR proteins are exposed on two-dimensional surface of replica and readily accessible for immunoreagents in SDS-FRL, whereas the images of postembedding labeling result from projecting gold particles only for surface antigens onto the entire thickness ( $\sim 90 \mathrm{~nm})$ of the section, and (2) epitopes are denatured by SDS and antibodies suitable for immunoblot analysis are likely to react similarly with proteins immobilized on the replica membrane. Second, labeling intensity for AMPAR obtained by SDS-FRL is less variable than that in postembedding materials, allowing reliable and quantitative comparison between different samples. Third, it is more efficient and quicker to analyze large number of individual synapses in replica samples than in postem- bedding serial ultrathin sections, which requires careful and time-consuming reconstruction.

Conversely, SDS-FRL also has potential limitations. First, identification of labeled profiles is often difficult from morphological features in replica because fracturing occurs randomly. In addition, although $5 \mathrm{~nm}$ carbon coat before the platinum shadowing in our method greatly increased sensitivity of immunolabeling, it gives alternate and variable appearance of IMPs, causing some difficulties in interpreting the images based on previous work with conventional shadowing. Therefore, labeling for marker proteins was necessary to identify three types of synapses in the molecular layer in the present study. Second, collecting synapses in replica materials could be influenced by some sampling bias because of variable probabilities for fracturing different types of synapse. Third, allocation of the target proteins to the $\mathrm{P}$ - and E-face is unpredictable and could depend on the types of synapse. Thus, to further support our conclusions obtained with SDS-FRL, we confirmed that AMPAR labeling in postembedding serial sections gave similar results, although with weaker and more variable signals.

In our SDS-FRL, we detect approximately one gold particle for one AMPAR channel, which is composed of four subunits. SDS-FRL established in the present study is therefore very useful for the estimation of AMPAR channel numbers and densities in synaptic sites. With careful evaluation of potential sampling problems, SDS-FRL proved to be a powerful complementary method to the conventional postembedding method.

\section{All synapses have AMPAR}

Although our postembedding analysis had much higher sensitivity than previous studies (Landsend et al., 1997; Zhao et al., 1998), we found that $13 \%$ (18 in 140) of PF-PC synapses were devoid of AMPAR labeling. In contrast, SDS-FRL showed that not only CF-PC and PF-interneuron synapses, which had at least 19 particles, but also all complete PF-PC synapses labeled for GluR $\delta 2$ $(n=52)$ were also labeled for pan-AMPA. This result seems to be in contrast with that obtained with electrophysiological recording of PCs in acute slice preparations from 12- to 16-d-old and adult rat (Barbour, 1993; Isope and Barbour, 2002). These studies claimed that the majority of PF-PC synapses are silent synapses. However, taking into consideration the maximum amplitude $(30-40 \mathrm{pA})$ of individual EPSCs in these studies and maximum number of AMPAR particles (150-200) in individual synapses in the present study, the response from $\mathrm{PF}-\mathrm{PC}$ synapses that have $<50$ particles (consisting of half the population of PF-PC synapses) should be smaller than $10 \mathrm{pA}$. Considering SD of the noise (5.8 pA) (Isope and Barbour, 2002), these synapses with small numbers of AMPARs might have been undetectable in these studies. Otherwise, the discrepancy may be ascribable to differences in sample preparations. It has been reported that slicing can cause drastic changes in synapses (Kirov et al., 1999) and loss of GluR1 and GluR3 proteins (Taubenfeld et al., 2002) in the hippocampus. In addition, we cannot exclude the possibility that immunoreactive AMPARs may be partly nonfunctional, although our previous data suggested a close correlation between 
number of functional AMPAR channels and immunogold particles in immature CF-PC synapses (Tanaka et al., 2005). Weak PF stimulation causes the local calcium influx in spines, which is abolished by AMPAR blockade (Denk et al., 1995; Finch and Augustine, 1998). Even without detectable currents in cell bodies, such weak synapses may have some roles in local regulation of the synaptic strength.

\section{Number of synaptic AMPAR in adult cerebellum}

The number and density of synaptic receptors in the CNS have so far been estimated only in limited examples. Our estimates in $\mathrm{CF}-\mathrm{PC}$ and $\mathrm{PF}$-interneuron synapses are larger than previous estimates for AMPAR density at mossy fiber inputs to cerebellar granule cells $(\sim 1000$ receptors $/ \mu \mathrm{m}^{2}$ ) (Silver et al., 1996) and mossy fiber synapses in the hippocampus $\left(\sim 500\right.$ receptors $\left./ \mu \mathrm{m}^{2}\right)$ (Nusser, 1999) and for the $\mathrm{GABA}_{\mathrm{A}}$ receptor density in cerebellar stellate cells $(\sim 1250$ receptors/ $\mu \mathrm{m}^{2}$ ) (Nusser et al., 1997) but lower than that of nicotinic acetylcholine receptors in neuromuscular junction (>8000 receptors $/ \mu \mathrm{m}^{2}$ ) (Fertuck and Salpeter, 1974). The density of AMPARs in PF-PC synapses is the lowest among these values, supporting the perceptron model for information storage in this type of synapses (Brunel et al., 2004).

\section{Input- and target-cell-specific AMPAR distribution}

We found distinct distribution of AMPAR numbers and densities in three different types of synapses in the molecular layer. These results suggest that postsynaptic neurons distinctly regulate the AMPAR expression at individual synapses according to the different presynaptic inputs. Furthermore, the same type of presynaptic neurons form synapses with distinct AMPAR expression depending on the different postsynaptic targets. Our finding of large variability of AMPAR numbers in $\mathrm{PF}-\mathrm{PC}$ is consistent with previous electrophysiological studies indicating large variability in synaptic responses to granule cell stimulation (Barbour, 1993). PF-PC synapses are known to undergo long-term depression (LTD) and perform key roles in motor learning (Ito, 1984). Moreover, PF-PC LTD is expressed by the reduction in the number of AMPARs in vitro (Wang and Linden, 2000; Xia et al., 2000). In living animals, learning involving $\mathrm{PF}-\mathrm{PC}$ synapses would be occurring continuously and cause the reduction of AMPAR expression in individual synapses, resulting in a large variability in synaptic weight distribution. In contrast, stable transmission is thought to be more important for $\mathrm{CF}-\mathrm{PC}$ and $\mathrm{PF}-$ interneuron synapses. To fire PCs consistently, a reliable connection with $\mathrm{CF}$ would be necessary. Interneurons have smaller synapses made by PF with much higher density of
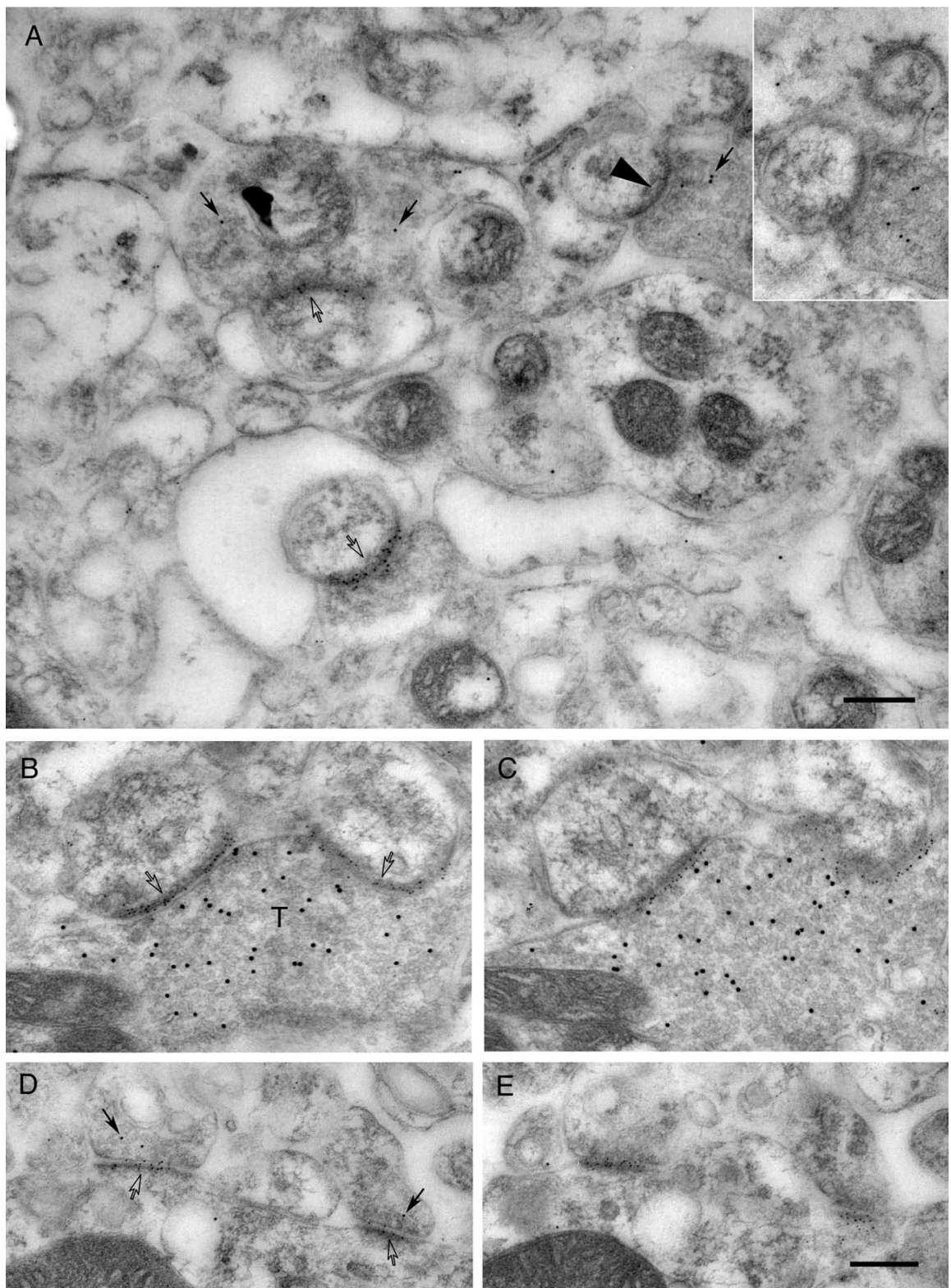

Figure 7. Localization of AMPARs visualized by postembedding triple labeling. $\boldsymbol{A}$, Immunolabeling for AMPARs (5 nm gold particles; open arrow) is found in some PF-PC synapses but not in others (arrowhead). PF varicosities were identified by labeling for VGluT1 (10 nm gold particles; arrows). B, C, Dense immunolabeling for AMPARs (open arrows) is found in CF-PC synapses identified by labeling for VGluT2 (15 nm gold particles) in terminals (T). D, E, Dense immunolabeling for AMPARs (open arrows) was found in PF-interneuron synapses identified by labeling for VGluT1 (arrows) in terminals. $\boldsymbol{A}$, Inset, $\boldsymbol{B}, \boldsymbol{C}$, and $\boldsymbol{D}, \boldsymbol{E}$ are consecutive ultrathin sections. Scale bars, $250 \mathrm{~nm}$ ( $\boldsymbol{B}-\boldsymbol{E}$ to same scale).

AMPARs compared with PCs. This situation could contribute to effective transmission by single quanta, allowing the different processing of synaptic input in this type of synapses (Carter and Regehr, 2002).

\section{AMPAR microdomain in PF-PC synapses}

Recent studies have suggested the existence of functional microdomains within synaptic membranes. Some studies have reported that the distribution of AMPARs may not be uniform over the postsynaptic density but more concentrated laterally, whereas NMDA receptors are located centrally (Matsubara et al., 1996; Kharazia and Weinberg, 1997; Somogyi et al., 1998; He et al., 2001). Other studies reported a uniform distribution over the postsynaptic membrane specialization (Nusser et al., 1994). 

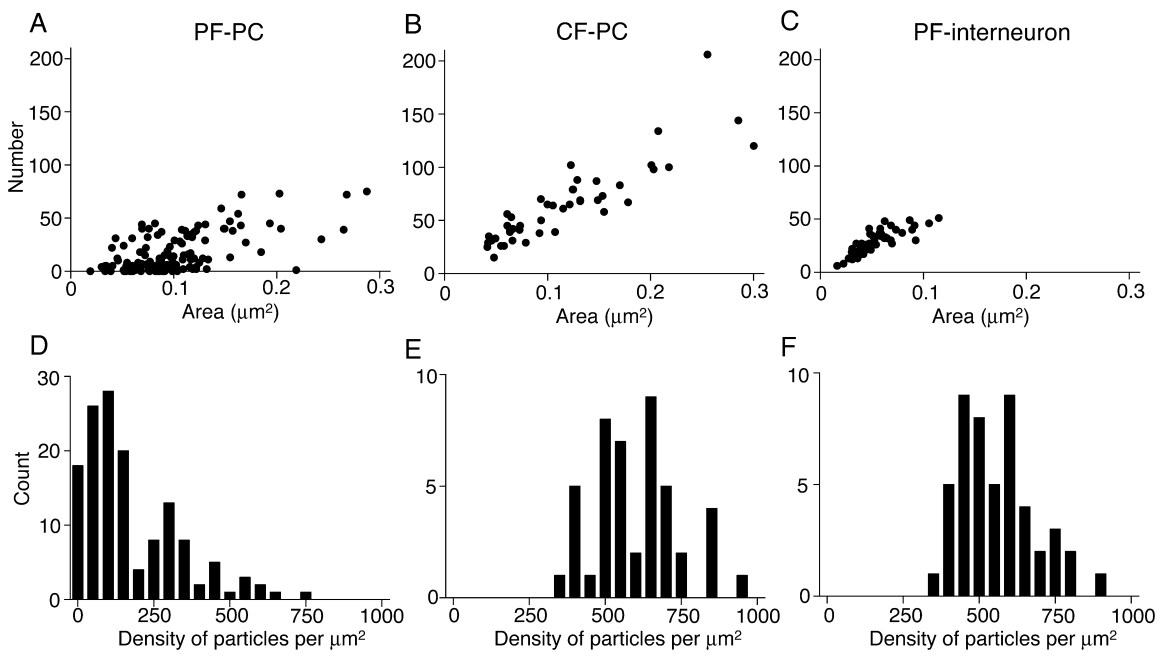

Figure 8. Number and density of immunogold particles for AMPARs in the molecular layer as revealed by postembedding method. $\boldsymbol{A}-\boldsymbol{C}$, Number of gold particles in PF-PC $(\boldsymbol{A}), \mathrm{CF}-\mathrm{PC}(\boldsymbol{B})$, and PF-interneuron $(\boldsymbol{C})$ synapse were measured in serial ultrathin sections and plotted against area of postsynaptic densities. Density of gold particles in $C F-P C(\boldsymbol{E})$ and $P F-$ interneuron $(\boldsymbol{F})$ synapses follows Gaussian distribution, whereas that in PF-PC (D) synapses is positively skewed.

These analyses are based on averaged distribution of immunogold particles detected by postembedding method. The high sensitivity and two-dimensional resolution of SDS-FRL have revealed irregular-shaped small AMPAR clusters within individual synaptic specialization in the present study. These clusters within PF-PC synapses were located not only laterally but also centrally depending on synapses. In contrast, AMPAR density at CF-PC and PF-interneuron synapses and GluR $\delta 2$ density at PF-PC synapses were very homogeneous over postsynaptic areas. These results may indicate the existence of microdomains selectively involved in AMPAR turnover regulated in individual PF-PC synapses and facilitate investigation of mechanisms and associated proteins responsible for such dynamism of synaptic organization.

\section{References}

Altman J, Bayer SA (1997) Development of the cerebellar system Boca Raton, FL: CRC

Barbour B (1993) Synaptic currents evoked in Purkinje cells by stimulating individual granule cells. Neuron 11:759-769.

Baude A, Nusser Z, Molnár E, Mcllhinney RA, Somogyi P (1995) Highresolution immunogold localization of AMPA type glutamate receptor subunits at synaptic and non-synaptic sites in rat hippocampus. Neuroscience 69:1031-1055.

Bredt DS, Nicoll RA (2003) AMPA receptor trafficking at excitatory synapses. Neuron 40:361-379.

Brunel N, Hakim V, Isope P, Nadal JP, Barbour B (2004) Optimal information storage and the distribution of synaptic weights: perceptron versus Purkinje cell. Neuron 43:745-757.

Carter AG, Regehr WG (2002) Quantal events shape cerebellar interneuron firing. Nat Neurosci 5:1309-1318.

Denk W, Sugimori M, Llinás R (1995) Two types of calcium response limited to single spines in cerebellar Purkinje cells. Proc Natl Acad Sci USA 92:8279-8282.

Dittman JS, Regehr WG (1998) Calcium dependence and recovery kinetics of presynaptic depression at the climbing fiber to Purkinje cell synapse. J Neurosci 18:6147-6162.

Fertuck HC, Salpeter MM (1974) Localization of acetylcholine receptor by ${ }^{125}$ I-labeled $\alpha$-bungarotoxin binding at mouse motor endplates. Proc Natl Acad Sci USA 71:1376-1378.

Finch EA, Augustine GJ (1998) Local calcium signalling by inositol-1,4,5trisphosphate in Purkinje cell dendrites. Nature 396:753-756.

Fujimoto K (1995) Freeze-fracture replica electron microscopy combined with SDS digestion for cytochemical labeling of integral membrane prorosci 19:2876-2886. teins. Application to the immunogold labeling of intercellular junctional complexes. J Cell Sci 108:3443-3449.

Harris KM, Landis DM (1986) Membrane structure at synaptic junctions in area CA1 of the rat hippocampus. Neuroscience 19:857-872.

Hashimoto K, Kano M (1998) Presynaptic origin of paired-pulse depression at climbing fibre-Purkinje cell synapses in the rat cerebellum. J Physiol (Lond) 506:391-405.

He Y, Hof PR, Janssen WG, Rothstein JD, Morrison JH (2001) Differential synaptic localization of GluR2 and EAAC1 in the macaque monkey entorhinal cortex: a postembedding immunogold study. Neurosci Lett 311:161-164.

Hioki H, Fujiyama F, Taki K, Tomioka R, Furuta T, Tamamaki N, Kaneko T (2003) Differential distribution of vesicular glutamate transporters in the rat cerebellar cortex. Neuroscience 117:1-6.

Hirai H, Launey T, Mikawa S, Torashima T, Yanagihara D, Kasaura T, Miyamoto A, Yuzaki M (2003) New role of $\delta 2$-glutamate receptors in AMPA receptor trafficking and cerebellar function. Nat Neurosci 6:869-876.

Hsu YH, Huang HY, Tsaur ML (2003) Contrasting expression of $\mathrm{Kv} 4.3$, an A-type $\mathrm{K}^{+}$channel, in migrating Purkinje cells and other post-migratory cerebellar neurons. Eur J Neurosci 18:601-612.

Isope P, Barbour B (2002) Properties of unitary granule cell $\rightarrow$ Purkinje cell synapses in adult rat cerebellar slices. J Neurosci 22:9668-9678.

Ito M (1984) The cerebellum and neural control. New York: Raven.

Ito M (2001) Cerebellar long-term depression: characterization, signal transduction, and functional roles. Physiol Rev 81:1143-1195.

Jonas P, Major G, Sakmann B (1993) Quantal components of unitary EPSCs at the mossy fibre synapse on CA3 pyramidal cells of rat hippocampus. J Physiol (Lond) 472:615-663.

Kashiwabuchi N, Ikeda K, Araki K, Hirano T, Shibuki K, Takayama C, Inoue Y, Kutsuwada T, Yagi T, Kang Y, Aizawa S, Mishina M (1995) Impairment of motor coordination, Purkinje cell synapse formation, and cerebellar long-term depression in GluR $\delta 2$ mutant mice. Cell 81:245-252.

Keinänen K, Wisden W, Sommer B, Werner P, Herb A, Verdoorn TA, Sakmann B, Seeburg PH (1990) A family of AMPA-selective glutamate receptors. Science 249:556-560.

Kharazia VN, Weinberg RJ (1997) Tangential synaptic distribution of NMDA and AMPA receptors in rat neocortex. Neurosci Lett 238:41-44.

Kirov SA, Sorra KE, Harris KM (1999) Slices have more synapses than perfusion-fixed hippocampus from both young and mature rats. J Neu-

Kulik A, Nakadate K, Nyíri G, Notomi T, Malitschek B, Bettler B, Shigemoto R (2002) Distinct localization of $G_{A B A}$ receptors relative to synaptic sites in the rat cerebellum and ventrobasal thalamus. Eur J Neurosci 15:291-307.

Landis DM, Reese TS (1974) Differences in membrane structure between excitatory and inhibitory synapses in the cerebellar cortex. J Comp Neurol 155:93-125.

Landsend AS, Amiry-Moghaddam M, Matsubara A, Bergersen L, Usami S, Wenthold RJ, Ottersen OP (1997) Differential localization of $\delta$ glutamate receptors in the rat cerebellum: coexpression with AMPA receptors in parallel fiber-spine synapses and absence from climbing fiber-spine synapses. J Neurosci 17:834-842.

Martin LJ, Blackstone CD, Levey AI, Huganir RL, Price DL (1993) AMPA glutamate receptor subunits are differentially distributed in rat brain. Neuroscience 53:327-358.

Matsubara A, Laake JH, Davanger S, Usami S, Ottersen OP (1996) Organization of AMPA receptor subunits at a glutamate synapse: a quantitative immunogold analysis of hair cell synapses in the rat organ of Corti. J Neurosci 16:4457-4467.

Miyazaki T, Fukaya M, Shimizu H, Watanabe M (2003) Subtype switching of vesicular glutamate transporters at parallel fibre-Purkinje cell synapses in developing mouse cerebellum. Eur J Neurosci 17:2563-2572. 
Momiyama A, Silver RA, Häusser M, Notomi T, Wu Y, Shigemoto R, CullCandy SG (2003) The density of AMPA receptors activated by a transmitter quantum at the climbing fibre-Purkinje cell synapse in immature rats. J Physiol (Lond) 549:75-92.

Nusser Z (1999) A new approach to estimate the number, density and variability of receptors at central synapses. Eur J Neurosci 11:745-752.

Nusser Z, Mulvihill E, Streit P, Somogyi P (1994) Subsynaptic segregation of metabotropic and ionotropic glutamate receptors as revealed by immunogold localization. Neuroscience 61:421-427.

Nusser Z, Cull-Candy S, Farrant M (1997) Differences in synaptic GABA receptor number underlie variation in GABA mini amplitude. Neuron 19:697-709.

Nusser Z, Lujan R, Laube G, Roberts JD, Molnar E, Somogyi P (1998) Cell type and pathway dependence of synaptic AMPA receptor number and variability in the hippocampus. Neuron 21:545-559.

Palay SL, Chan-Palay V (1974) Cerebellar cortex. New York: Springer.

Pereda A, O’Brien J, Nagy JI, Bukauskas F, Davidson KG, Kamasawa N, Yasumura T, Rash JE (2003) Connexin35 mediates electrical transmission at mixed synapses on Mauthner cells. J Neurosci 23:7489-7503.

Rash JE, Yasumura T (1999) Direct immunogold labeling of connexins and aquaporin-4 in freeze-fracture replicas of liver, brain, and spinal cord: factors limiting quantitative analysis. Cell Tissue Res 296:307-321.

Rash JE, Davidson KG, Kamasawa N, Yasumura T, Kamasawa M, Zhang C, Michaels R, Restrepo D, Ottersen OP, Olson CO, Nagy JI (2005) Ultrastructural localization of connexins ( $\mathrm{Cx} 36, \mathrm{Cx} 43, \mathrm{Cx} 45)$, glutamate receptors and aquaporin-4 in rodent olfactory mucosa, olfactory nerve and olfactory bulb. J Neurocytol 34:307-341.

Sato K, Kiyama H, Tohyama M (1993) The differential expression patterns of messenger RNAs encoding non- $N$-methyl-D-aspartate glutamate receptor subunits (GluR1-4) in the rat brain. Neuroscience 52:515-539.

Silver RA, Cull-Candy SG, Takahashi T (1996) Non-NMDA glutamate receptor occupancy and open probability at a rat cerebellar synapse with single and multiple release sites. J Physiol (Lond) 494:231-250.

Silver RA, Momiyama A, Cull-Candy SG (1998) Locus of frequencydependent depression identified with multiple-probability fluctuation analysis at rat climbing fibre-Purkinje cell synapses. J Physiol (Lond) 510:881-902.

Smith MA, Ellis-Davies GC, Magee JC (2003) Mechanism of the distance- dependent scaling of Schaffer collateral synapses in rat CA1 pyramida neurons. J Physiol (Lond) 548:245-258.

Somogyi P, Tamás G, Lujan R, Buhl EH (1998) Salient features of synaptic organisation in the cerebral cortex. Brain Res Brain Res Rev 26:113-135.

Takumi Y, Ramírez-León V, Laake P, Rinvik E, Ottersen OP (1999) Different modes of expression of AMPA and NMDA receptors in hippocampal synapses. Nat Neurosci 2:618-624.

Tanaka J, Matsuzaki M, Tarusawa E, Momiyama A, Molnar E, Kasai H, Shigemoto R (2005) Number and density of AMPA receptors in single synapses in immature cerebellum. J Neurosci 25:799-807.

Taubenfeld SM, Stevens KA, Pollonini G, Ruggiero J, Alberini CM (2002) Profound molecular changes following hippocampal slice preparation: loss of AMPA receptor subunits and uncoupled mRNA/protein expression. J Neurochem 81:1348-1360.

Thach WT (1968) Discharge of Purkinje and cerebellar nuclear neurons during rapidly alternating arm movements in the monkey. J Neurophysiol 31:785-797.

Triller A, Choquet D (2005) Surface trafficking of receptors between synaptic and extrasynaptic membranes: and yet they do move! Trends Neurosci 28:133-139.

Vissavajihala P, Janssen WG, Hu Y, Gazzaley AH, Moran T, Hof PR, Morrison $\mathrm{JH}$ (1996) Synaptic distribution of the AMPA-GluR2 subunit and its colocalization with calcium-binding proteins in rat cerebral cortex: an immunohistochemical study using a GluR2-specific monoclonal antibody. Exp Neurol 142:296-312.

Wang YT, Linden DJ (2000) Expression of cerebellar long-term depression requires postsynaptic clathrin-mediated endocytosis. Neuron 25:635-647.

Xia J, Chung HJ, Wihler C, Huganir RL, Linden DJ (2000) Cerebellar longterm depression requires PKC-regulated interactions between GluR2/3 and PDZ domain-containing proteins. Neuron 28:499-510.

Zhao HM, Wenthold RJ, Wang YX, Petralia RS (1997) $\delta$-glutamate receptors are differentially distributed at parallel and climbing fiber synapses on Purkinje cells. J Neurochem 68:1041-1052.

Zhao HM, Wenthold RJ, Petralia RS (1998) Glutamate receptor targeting to synaptic populations on Purkinje cells is developmentally regulated. J Neurosci 18:5517-5528. 